\title{
Aligning digital literacy and student academic success: Lessons learned from COVID-19 pandemic
}

\author{
Veronica Udeogalanya \\ Medgar Evers College, City University of New York, USA
}

\section{Keywords}

Academic Success, Aligning, COVID-19, Digital Literacy, Student, Pandemic

\begin{abstract}
In this paper the alignment of computer and digital literacy as well as student academic success were examined. Lack of adequate functional digital literacy training and the unreadiness of higher education institutions for the impact of random shocks such as COVID-19 pandemic has gravely affected teaching and learning.

The purpose of this paper is to make the case for preparedness of students to meet the needs of technology jobs by mandating and aligning digital literacy and student success. As COVID-19 Pandemic was spreading through the communities of the United States, institutions of higher education transitioned to fully online teaching and learning. Prior to the pandemic, fully online education was secondary to face-to-face format. Only about $20 \%$ of classes were fully online while $80 \%$ were face-to-face. Digital literacy was given a token treatment as a percentage of the entire curriculum and relegated to only the departments of computer information systems and computer sciences. Faculty, students, staff, families, and communities were not trained for the intensity of fully online education as the only format. Many of them never heard of most of the digital literacy tools. Both faculty and students were forced to learn the use of computers and digital literacy tools to survive the spring 2020 semester. Low-income families were left to the operational schedules of local libraries, many of whom did not have internet presence. The institutions provided limited training for faculty and students to meet the urgency of the time. Faculty and students were forced to purchase expensive tools and hardware to withstand the intensive demand of teaching and learning. Many students were overwhelmed by the pressure of the new way of learning; some dropped out of school while many performed very poorly in their examinations which negatively impacted their overall grade point averages. One year later in spring 2021, the student success outcomes have barely changed. At the same time, technology is advancing despite the raging COVID pandemic. Millions of technologyenabled jobs remain unfilled while millions of university graduates are unemployed. There continues to be a mismatch between current job requirements in the industries and graduating students' skills.

This paper discusses the indispensable value of building computer and digital literacy training into all undergraduate curriculums. We argue for mandated computer and digital literacy exit skills assessment test for all graduating students irrespective of their discipline. We also make the case for increased institutional investment in faculty training in computer and digital literacy readiness. There are a number of remedies suggested to address the speed of advancement in technology, faculty and student functional mastery of basic computer and digital literacy skills. We conclude that all institutions must be proactive rather than reactive to systemic shocks by preparing students for academic success and technological readiness for today's job markets.
\end{abstract}

\section{Introduction}

Digital literacy is crucial to academic success, particularly for first-generation college students who have no one to emulate. Many institutions of higher learning are now concerned with digital literacy readiness as a result of the forced shutdown due to the spread of Covid-19 in the spring of 2020. Digital literacy is defined as the ability to find, evaluate, share and create content using the internet (Widana, 2020). Covid-19 pandemic caused digital literacy skills to permeate the classroom and become requirements for both faculty and students. We live in an internet age that requires specific skills and working Americans rely on the internet to do their jobs. Digital literacy skills, therefore, have become essential to academic, career and interpersonal success. It follows that the more digitally literate faculty are, the more they will employ these skills in the classroom, which transfers to the students. However, not 
all students have access to a computer and the Internet. Those that have access are able to find the answers to not only simple questions, but also complex problems. Those students that do not have access or cannot afford to have access to information are at a grave disadvantage. As a survival strategy, students who lack digital literacy access usually go to public places such as the libraries, cafes, or eateries to use the internet. Covid-19 pandemic denied these students the opportunity to avail themselves of such lifeline of available digital information because everybody had to quarantine indoors for safety while teaching and learning continued. Higher education was thrown into confusion as the Covid-19 pandemic occurred in the middle of the semester. Faculty and students had to continue the business of teaching and learning. The difference was that the paradigm shifted from face-to-face instruction to fully online. Most students were required to use digital literacy tools that they never used before. They were greatly unprepared for what confronted them. For deep learning, faculty must provide students with the additional digital skills required. However, to be effective, faculty must learn such skills first to be able to transfer to the students.

Research shows that while students may be adept at using digital tools, their understanding of what these tools can do is often limited (Doucet et al., 2020). For example, students use Instagram to post photos but do not think of using the same platform for art or history projects. They record themselves with a voice memo app but do not realize those apps could also be used for class projects or a historical narrative piece. Digitally literate faculty know how to inspire students to use today's technology as a powerful toolset to expand their learning opportunities. They also understand that it is less about the technology itself than it is about the tailored experience the technology can provide to each student. This is what drives differentiation and can make it powerful and highly targeted to students' individual needs. The emergency created by the Covid-19 pandemic destroyed this normal transfer of learning sequence. The faculty-student learning dynamic was disrupted. Students were left to figure things out on their own. Many of these students are first-generation undergraduates with no role models. Thus, as faculty master digital literacy with their lectures, they can collaborate with peers to share technology and work toward improving learning outcomes for their students, but they were hindered by the crisis of the raging pandemic that was killing millions of people. For students to get the most out of technology and the benefits it offers, they needed to know how to use it to process, deliver and receive digital information most effectively but they too were handicapped by the deadly pandemic. Majority of Faculty realized during COVID-19 that digital literacy was a critical skill for today's students because it directly impacts their academic performance, but they were also blindsided by the virus. Against this chaotic background, institutions of higher education were faced with aligning digital literacy and student academic success during Covid-19 pandemic.

\section{Problem}

Institutions of higher education prior to the Covid-19 pandemic treated digital literacy and computer education in general as a secondary requirement. The pandemic has forced the attention of higher education administration to focus on the need for intentionally designed online learning for the future. This necessary shift has made it possible for the institutions to continue teaching and learning amid the COVID-19 pandemic and has also presented a myriad of challenges for faculty and students. Faculty, through intensive professional development funded by the institutions, quickly adapted their pedagogies to the technologies at hand. However, students and their families have continued to struggle with the more basic need of accessibility as the campus computer labs, technical assistance and high-speed Wi-Fi ordinarily taken for granted remain unavailable. The challenge of keeping students engaged with their instructors as well as their peers remained a big challenge throughout the return to studies. These challenges are real and have prompted most institutions to reexamine the concept of "student success" and what it means to deliver on the expectations and needs of students. Learning has remained virtual, and many institutions are considering making online education a center piece of teaching and learning for the foreseeable future. The COVID-19 pandemic has presented institutional leaders and faculty with a catalyst for change. In response to this pedagogical shift, many institutions are using this challenge as an opportunity to connect with local organizations and community partners to provide educational opportunities that align with current jobs. Covid-19 pandemic has thus forced various sectors of the economy to seek answers in increasing student enrollment, retention, and graduation, all of which have been negatively impacted by the global Covid-19 crisis. 
Lack of adequate functional digital literacy training as well as the unreadiness of higher education institutions for the impact of random shocks such as COVID-19 pandemic has gravely affected teaching and learning. As the Pandemic was spreading through the communities of the United States, institutions of higher education pivoted to fully online teaching and learning. Prior to the pandemic, fully online education was secondary to face-to-face format. Only about $20 \%$ of classes were fully online while $80 \%$ were face-to-face (UNESCO, 2020). Digital literacy was given a token treatment as a percentage of the entire curriculum and relegated to only the departments of computer information systems and computer sciences. Faculty, students, staff, families, and the communities were not trained for the intensity of fully online education as the only format available during the pandemic. Many students never heard of most of the digital literacy tools used for learning. Both faculty and students were forced to learn the use of computers and digital literacy tools to survive the spring 2020 semester. Low-income families were left to the operational schedules of local libraries, many of whom did not have internet presence. The institutions provided limited training for faculty and students to meet the urgency. Faculty and students were forced to purchase expensive tools and hardware to withstand the required intensive demand of teaching and learning. Many students were overwhelmed by the pressure of the new way of learning; some dropped out of school while others performed very poorly in their examinations which negatively impacted their overall grade point averages. One year later in spring 2021, the student success outcomes have barely changed. At the same time, technology is advancing, and the world is moving on despite the raging COVID pandemic.

Millions of technology-enabled jobs remain unfilled while millions of university graduates are unemployed. There continues to be a mismatch between current job requirements in the industries and graduating students' skills. COVID-19 has pushed the world in a new direction with regards to education. Digital literacy does not require that faculty become experts, but it does require that they understand the digital tools that can unlock their deeper teaching potential. Digital citizenship is widely defined as the appropriate and responsible use of technology (Stratford, 2020). Key to ensuring that students understand, and practice digital citizenship is to make it a core part of all curricula and to model ethical digital behavior. Faculty should intentionally weave discussions and elements of digital citizenship into lectures that involves technology, so students can see the relevance of digital citizenship. Not only do students need to know how to find information but they also need to know how to evaluate the content found. With $76 \%$ of teenagers using social media, according to the Pew Research Center (2021), it is important that teachers address ethical digital citizenship when teaching digital literacy. Helping students grasp the potential implications of their digital footprint is one critical area of importance for faculty designing digital literacy curricula. According to the Pew Research Center, ethical social media use is a critical component of any digital literacy curriculum, as a student's actions on social media can have ripple effects not only today but for years into the future. Faculty should educate students on available tools and how to best utilize them, but the pandemic has made this task extremely difficulty. Building digital literacy resiliency into the curriculum and educational systems is a proactive way to absorb systemic shocks such as the COVID-19 pandemic. Digital literacy is a big challenge that faculty, students, staff, administrators and the community together must handle. As most faculty goal is the success of their students, intentional alignment of digital literacy skills as well as effective use of its tools, must therefore be foremost in educational institutional agenda. Success in students' learning and progress at their jobs after graduation manifest this joint effort. This paper believes that digital literacy proficiency is the key to student success and should be central in future curriculum design and implementation.

\section{Literature Review}

All over the world, technology has become ingrained into personal, professional, and social aspects of our lives. According to a 2014 report by the U.S. Federal Communications Commission, 31 percent of urban schools and 41 percent of rural schools do not have an Internet connection. Students in these institutions struggle to take advantage of the tools, platforms, apps and resources available to their connected peers. But this digital divide is not just in schools, there is also a lack of access to devices and broadband at home exacerbating the digital divide. This was the reality faced by many students and their families prior to the devastating impact of Covid-19 pandemic. The reality is that educators must have digital literacy skills to better equip students to become productive citizens of society. Digital literacy 
means having the knowledge and ability to use a wide range of technology tools for a variety of purposes (Mantiri, Hibbert, \& Jacobs, 2019). According to Widona (2020), "Digital literacy is the ability to use and create technology-based content, including finding and sharing information, answering questions, and interacting with others and computer programming". The Covid-19 pandemic outbreak forced colleges and universities to shut down. This made the demand for online education worse and the impact of the lack of digital literacy skills more pronounced. Progress in teaching and learning was thus at the mercy of digital literacy, education, and tools. Faculty and their students were made vulnerable and educational institutions were struggling to find options to deal with the Covid-19 pandemic and its inherent challenges. Educators have a social and professional responsibility to be digitally literate (Widana, 2020).

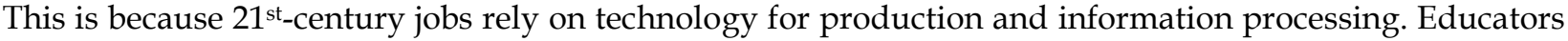
are expected to assist with closing the digital divide between subpopulations of students to ensure adequate equity and to provide them with the opportunity to compete on a global scale post-secondary education. However, the question became that of how prepared faculty for the immense expectations were that the reality of the pandemic created.

On the other hand, companies are seeking digitally literate employees to help them maximize production, create new products, and manage the daily business operations. Students need to be well versed in digital literacy tools and systems management databases to support companies and businesses within our society. Faculty must know how to successfully integrate technology with pedagogy to not only engage students, but to ensure students can effectively use digital tools to support the workplace and businesses for centuries to come. Even entrepreneurs use digital literacy to promote and sustain their businesses. Again, we must consider the readiness of faculty with the extent of digital literacy skills that the moment required in the face of the devastating impact of the deadly pandemic. According to Casey and Bruce (2011), "Teaching with digital technology prepares students for future participation in an evolving society where new media practices are deeply embedded in the associated structures and processes". It is important for faculty and students to have competency skills in digital literacy, they noted. "Many established businesses have been uprooted and replaced by automation and digitization systems" (Widana, 2020). Faculty must, therefore, be adaptable towards technology use, be open minded and willing to learn from students, and stay abreast of technological advancements, (Mantiri, Hibbert, \& Jacobs, 2019). The reality of Covid-19 has forced faculty to rethink the survival of their curriculum and programs as student enrollment continues to decline. Many faculties are actively collaborating with one another across disciplines to improve online teaching methods. There are opportunities for cooperation, creative solutions and willingness to learn from others and try new tools just as educators, parents and students share similar experiences (Doucet et al., 2020). Many educational organizations in the industries are offering their tools and solutions for free to help support teaching and learning in a more interactive and engaging environment in the face of the pandemic. Exclusive online learning forced on society by the pandemic has provided the opportunity to teach and learn in innovative ways. How prepared are faculty, students, administrators, staff, families, and communities for this challenge?

During this Covid-19 pandemic, the greatest concern remains how to protect and save our faculty, students, staff, administration and the community at large by strengthening the higher education industry. Basilaia et al., 2020 stressed the urgency of mastery of digital literacy tools as a vital response to teaching and learning changes such as the chaos of Covid-19. Faculty are encouraged to focus on how to hone students' technology skills by increasing student engagement, assessment, and feedbacks, thus creating effective and meaningful learning environments (Brianna et al., 2019). The 20 students interviewed by this study during the spring 2020 semester recounted the stress, fear, anxiety, depression, and insomnia that they were dealing with as they studied. Many complained that they had difficulty focusing and concentrating on their coursework. They worried that they would fail their examinations. Favale et al., 2020 concurred and emphasized the challenges of fully online education during crisis such as loss of direct communication and human touch; varied degrees of student capabilities and confidence levels. They stressed that many students do not feel comfortable while learning online thus leading to increased frustration and confusion. Affouneh et al., 2020 cautioned institutions to take account of developing and enhancing the quality of virtual courses delivered during crises. They highlighted the time and cost involved in online education because a considerable amount of investment is needed for 
getting the devices and equipment, maintaining the equipment, training the human resources, and developing the online content. The reality is that many faculties and students are from low-income and underrepresented communities. They are faced with financial challenges, lack of access, and affordability issues. Ensuring digital equity becomes an issue with these populations worsened by the Covid-19 pandemic. Effective and efficient educational system needs to be developed to impart teaching and learning via online.

For too many faculties, students, and staff, unavailability of digital tools, internet connections, Wi-Fi, computers, and other educational apps remain a major obstacle to teaching and learning. This continues to exacerbate the digital divide. The Covid-19 pandemic is a wake-up call for institutions of higher education. Many faculties and students have never really practiced fully online teaching and learning. As part of lessons learned from the pandemic, which is still on-going, educators can learn a lot from their experiences since the spring semester of 2020. As a result, colleges and universities can develop step-bystep guidelines on best available tools, how to access such tools, improving curricula, and presenting them in various formats, building in feedbacks, thus improving student success. In today's complex digitally networked environment, the briefly reviewed literature raise pertinent issues: how we teach, how we learn, and how we educate our students in the $21^{\text {st }}$ century. How efficiently have faculty and students adjusted to the sudden pandemic? What educational transformation have occurred and what impact do they have on student success? What provisions are being made for faculty and students to improve their skills? What are the current implications and challenges of digital literacy for students' academic success? This paper presents a preliminary effort at aligning digital literacy and student academic success. The new normal of connected classrooms, networked learning, and digital skills gaps among many faculties and students has made teaching and learning conversations more urgent.

The COVID-19 pandemic led to lockdown and closures of schools, training institutes and higher education facilities in most countries including the United States. There has been a paradigm shift in the way faculty deliver quality education through various online platforms. The online learning, distance and continuing education have become a panacea for this unprecedented global pandemic, despite the challenges posed to both faculty and the students. Transitioning from traditional face-to-face learning to online learning posed an entirely different experience for both the students and faculty with little or no other alternatives available. There is now a pressing need to innovate and implement alternative educational and assessment strategies (Dhawan, 2020). E-learning tools have played a crucial role during this pandemic, helping colleges and universities to facilitate student learning during the forced closures (Subedi et al., 2020). Most students with a fixed mindset of education and learning found it difficult to adapt and adjust, while the students with a growth mindset quickly adapted to the new learning environment. Many students at home and/or living space have undergone psychological and emotional distress and have been unable to engage productively with coursework (Petrie, 2020). According to Murgatrotd, 2020, the following broadly identified challenges with e-learning are accessibility, affordability, flexibility, learning pedagogy, life-long learning and educational policy. Also, the study noted that there are practical issues around physical workspaces conducive to different ways of learning. Many students were among the most vulnerable group who were weak in learning and continue to face difficulties. Some academically competent learners from poor background are unable to access and afford online learning (Sintema, 2020).

Cluver et al. 2020 noted that not only did students lack daily access to their campuses and the basic institutional supports that institutions provide, but they also lost out on group activities, team sports, and recreational options such as pools and gyms. Hodges et al. 2020 observed that what we know from research is that effective online learning results from careful instructional design and planning, using a systematic model for design and development. The design process and the careful consideration of different design decisions have an impact on the quality of the instruction. They suggested that it is this careful design process that is missing during the Covid-19 pandemic. As Hodges et al., 2020 emphasized when exploring how colleges and universities were coping with the sudden and rapid shift to remote learning, understanding the current circumstances required distinguishing between online or remote learning generally. They also noted that weak systems of support, including lack of professional 
development on how to integrate computers into instruction, have left faculty less than optimally equipped to teach during the pandemic.

In addition, Anderson 2020; Azzi-Hucktigran and Shmis 2020, noted that a certain level of preparedness is critical in order to provide an effective response at the onset of a crisis, and to "prepare, cope, and recover". They noted that the COVID-19 crisis has exacerbated the well-documented opportunity and enrichment gaps that put low-income students at a disadvantage relative to their betteroff peers. They also discuss how the pandemic has exacerbated the limitations of standardized assessments, especially when used to measure performance gaps in education. All of the above challenges, mean more stress for students. For those students who were already living in cramped and less-than-ideal situations, having all family members in the house makes the regular challenges of daily life much greater and learning more difficult. Increased incidences of abuse due to confinement, stress, and lack of access to outside support further affirm the urgency of addressing the stressors that are affecting families and, in turn, student's development and ability to learn (Stratford 2020; and Greeley 2020). It is in these challenging contexts of economic insecurity and housing instability that students and faculty were suddenly transitioning to remote learning. Black and Hispanic students are more likely to lack this access according to García, Weiss, and Engdahl 2020; Tinubu Ali and Herrera 2020. A Southern Education Foundation report on class- and race-based disparities during the COVID-19 crisis finds similar disparities in access to the resources needed for online learning. It notes that nearly one in five African American students and a slightly greater share of students in low-income households have no access to the internet at home (Tinubu Ali and Herrera 2020). It is against the background of all the above challenges that this paper attempts to study ways to better align digital literacy education, its tools, and student academic success. The paper hopes to highlight the needs of closing existing digital literacy education gaps among students particularly those from low-income and underrepresented communities.

\section{Research Methodology}

The present work is an exploratory research based on investigative techniques. It is a fundamental and qualitative research which explores the current knowledge on digital literacy and its impact on student academic success during the Covid-19 pandemic. Existing literature on digital literacy was reviewed to gain a general understanding of various aspects of the concept and helpful takeaways. A preliminary survey of 20 face-to-face students was also conducted to understand their experiences during the mandated fully online learning in spring of 2020. As courses remain online, it is critical for higher education institutions to seek to better understand what students believe they need to be successful and engaged. Consequently, this paper interviewed the 20 students to hear their voices with regards to their quest for academic success. The Covid-19 pandemic that necessitated a shift from face-to-face to fully online has presented colleges and universities with the challenge of transferring hands-on learning experiences to an online format that needs to survive by being collaborative and rigorous enough to prepare students for real-world application despite the pandemic. The students' voices, expectations, and ideas deserve to be heard and the industries demand it. This paper is an initial insight into an attempt at aligning student digital literacy skills requirements and success in their academic pursuit during Covid-19 pandemic.

\section{Discussion}

Many colleges and universities around the world temporarily postponed classroom teaching and learning as a result of the spread of the Covid-19 pandemic. Teaching and learning activities were then subsequently changed from predominantly face-to-face instructions to fully online. Twenty students in the School of Business, Medgar Evers College of the City University of New York were interviewed in this preliminary study. Of the 20 students interviewed, 13 (65\%) were full-time and 7(35\%) were part-time. The age distribution of the participants was as follows: 18-25 (5 students); 26-35 (6 students); and 36-45 (9 students). 10 of the students lived in Brooklyn; 6 lived in the Bronx; and 4 students lived in Queens. All the students reported that taking fully online courses had a negative effect on them and they were afraid that they were going to fail their tests and examinations. Some of the students said that they were thinking of dropping out of school because they felt overwhelmed. $9(45 \%)$ of the students used their smart phones to access the course materials online; $6(30 \%)$ used laptops, while $5(25 \%)$ shared personal computers with 
other members of their families. These responses were similar to the study by Lazarus et al. (2017) who showed that the most popular device that students used to access the online materials was the smart phone followed by laptop, while the least used tool was the personal computer. Many of the respondents mentioned that their studies were constantly interrupted because the devices did not work causing them to miss deadlines or repeat assignments. As a result of these reported interruptions, some respondents informed us that they had to go to the homes of friends and relatives to complete some of their assignments. Others reported going to public places to use the internet for course work. This presented instances of unequal access to computers and the internet thus altering the effectiveness of their learning. Of the 20 respondents, 10 (50\%) reported that they were greatly affected by the Covid-19 pandemic; 7 $(35 \%)$ said that they were considerably affected; and $3(15 \%)$ reported that they were slightly affected. None of the 20 students reported that they were not negatively affected by the pandemic. $8(40 \%)$ of the respondents reported that their instructors used Zoom as the means of delivery of their virtual class sessions; while $12(60 \%)$ reported that their instructors used Blackboard. They reported that they had access to recorded materials if they missed classes which was very helpful to them.

The most common problems reported by the students included the lack of availability of internet when they needed it most, and the interruptions in speed. Many of the students reported that they could not afford the cost of internet, and that they suffered from lack of availability of electronic devices to access the internet. Another major problem that the students reported was that they missed the face-toface interactions with their professors and classmates. They mentioned that learning online felt unreal and very artificial. When pushed to explain what they meant by "artificial", they replied that teaching and learning was not the same as when they came to class. When asked to summarize what challenges they were experiencing with their classes, their final responses included internet interruptions; cost of devices and hardware; access to the internet; loneliness due to little or no interactions between students and the instructors; little or no feedback from some instructors; easy to fall asleep while attempting to study; and panic, frustrations, and low self-esteem. When asked what can faculty or the College do to help them succeed academically, their replies included reduce stress by assigning fewer coursework; provide computers, laptops, and IPADs for students; faculty should be more patient with students; faculty should explain their assignments more; faculty should review tests and examinations before posting the assignments; the College should train the faculty on online skills so that they can better assist the students; and the College should provide more resources to students that can make course materials more accessible. When the students were asked what factors, they considered to be the main drivers of academic success, they mentioned hands-on instruction (83\%), faculty quality (81\%), and technology availability $(87 \%)$. From the students' perspective, digital literacy and its tools forced on education by the crisis has resulted in changes to instructional delivery that are here to stay. The students reported that they liked learning online, but they wanted to be trained to use the tools first before doing the assignments. Most of the students sounded enthusiastic. The reality of Covid-19 has made it to become evident to institutions of higher learning that connecting faculty and students with technology and helping students connect with the job markets is essential to both the success of students as well as the success of colleges and universities themselves. Most proposed new programs now focus on enabling faculty, technologists, instructional designers, and administrators to collaborate to forge a pathway to the future, celebrating and supporting each other and their students along the way.

This paper discusses the indispensable value of building computer and digital literacy training into all undergraduate curricula. We argue that programs may want to consider mandated computer and digital literacy exit skills assessment test for all graduating students irrespective of their discipline. This will guarantee readiness for any sudden changes such as the Covid-19 pandemic. We also make the case for increased institutional investment in faculty training in computer and digital literacy readiness. This is because armed with such skills, faculty will be ready to transfer what they know to their students. There are a number of remedies suggested in the above reviewed literatures to address the speed of advancement in technology and faculty and student functional mastery of basic computer and digital literacy skills. We conclude that all institutions must be proactive rather than reactive to systemic shocks by preparing students for academic success and technological readiness for today's job markets. This paper makes the case for preparedness of students to meet the needs of technology jobs by mandating and 
aligning digital literacy and student success. We argue that there is an urgent need to create a culture of digital literacy learning, collaboration, and sharing among educators, students, families, and the communities. Therefore, to meet the industry expectations, colleges and universities need to integrate digital literacy competencies into the various curricula. Intentional instructional practices that enhance learning and engagement among faculty, students, staff, administrators, and the community are required for the survival of teaching and learning in particular, and the institutions of higher education in general. Realizing this, many colleges and universities are providing loaner equipment such as laptops, PCs, iPads, and other resources but the demand far exceed the current supply. In addition, faculty development trainers are using digital literacy concepts to train new faculty who will coordinate online teaching and learning. More needs to be done as the students' academic success depends on the institutional success.

Since the pandemic affected all units in the institutions, there is a great need for support, collaboration, and a multi-disciplinary approach to understanding and learning the necessary knowledge and skills required to fully participate in the digital age. Embracing such a culture by all educators will knock down feelings of isolation among faculty and encourage more cross-disciplinary engagement and collaboration. Resources such as intentional digital skills development and training; increase in creative hands-on activities; engaging the students; assessing the engagement exercises; and using the feedback from the assessment to revise the curricula are in urgent need. Institutions of higher education need to increase the development of opportunities that encourage faculty collaboration; sharing of ideas among colleagues; networking and professional relationships; and measurable action steps that can be duplicated. The affordability and accessibility to online infrastructures for all students of varied economic backgrounds are still a challenge and need to be expanded. Students with special needs having learning difficulties, such as hearing impairment, visual impairment and mobility disabilities, require additional funding for training with support and guidance. The demand for support for these group of students remain great and hinder the learning of this group of students especially during the Covid-19 pandemic. Another key point is that faculty are concerned about plagiarism and other forms of cheating as all students' assignments and examinations are carried out from home. It is challenging to find the authenticity of the work and the actual learning taking place. Colleges and universities need to invest in assessment tools that will increase faculty confidence in the authenticity of students' work.

\section{Conclusions and Suggestions for Further Studies}

The current study is preliminary and have shown that COVID-19 pandemic lockdown affected the academic performance of students in various institutions of higher education. Faculty and students were forced to use online education to keep the art of teaching and learning up and running. It has not been easy for the students, faculty, staff, administration, families, and the communities. However, the main challenge and impact falls more on students whose future depends on their performances. Since most of the learning is assessed semester-by-semester, time is of great essence for the students because it is very costly to repeat semester's work due to no fault of theirs. Many of them did not choose fully online learning. The students' overall GPA for 2019-2020 academic year and the 2020-2021 academic year may be negatively impacted by the pandemic. The frustrations and stress if not addressed may negatively impact the student enrollment in institutions of higher education. The question then becomes what faculty as a group is willing to do about these out cries from our students and some faculty.

Our profession cannot survive empty classrooms if the student enrollment declines are not addressed. Planning, monitoring, assessment, training, collaboration, networking, adequate technical support, and sharing is the answer. Embracing digital literacy education and the relevant tools as the culture by all involved in the business of education may guarantee the provision of the skills to withstand most future random systemic shocks. Based on this preliminary study, students think that it is difficult to fulfill the academic competencies with only online education. They would prefer a combination of both online and face-to-face education. Based upon faculty responses, many would use hybrid pedagogy embracing the best aspects of both worlds, thus engaging students in face-to-face class sessions while employing digital literacy tools to enhance teaching and learning. By so doing, students will benefit from both world of educational practices and therefore increase their academic successes. In the end, we may successfully align digital literacy and its tools with increased student academic success. Time and further research will provide evidence. Furthermore, we can increase our knowledge by revisiting these 20 
students and checking their grades from Spring 2020 and Fall 2020 to see if their fears and concerns about their grades were founded. Moving forward, Covid-19 pandemic has taught us that technology is key to communication and continued teaching and learning in the era of severe economic shocks. Schools of business and other units must become more resilient to functional online teaching and learning. Consequently, a robust digital literacy and tools acquisition must be fundamental and a prerequisite for all curricula. Such digital literacy infrastructure must be so strong that it can withstand all crises. Both faculty and students must undergo pre- and post-digital skills mastery tests that demonstrate such competency.

Further exploration and investigation on the alignment of digital literacy and student academic success during Covid-19 pandemic is an area for more research. The affordability and accessibility for all the students of varied economic background is identified as a challenge, for which the educational tools developer could focus on improving by producing cheaper but effective alternatives. Institutional administration policy level intervention and support are fundamental to the success of any programs, strategies, and activities. Making online teaching creative, innovative, affordable and interactive through user-friendly tools is another area for more research and development. One of the lessons learnt from the COVID-19 pandemic is that faculty and students should embrace change and be oriented on use of different online educational tools. As a result, after the COVID-19 pandemic when normal classes resume, faculty and students should be encouraged to continue using such digital literacy tools to enhance teaching and learning. This should be a win-win scenario for all involved in the business of education.

\section{References}

Affouneh, S., Salha, S., N., \& Khlaif, Z. (2020). Designing quality e-learning environments for emergency remote teaching in coronavirus crisis. Interdisciplinary Journal of Virtual Learning in Medical Sciences, 11(2), $1-3$

Anderson, Allison. 2020. COVID-19 Outbreak Highlights Critical Gaps in School Emergency Preparedness, The

Brookings Institution March 11, 2020.

Azzi-Hucktigran Kaliope, and Tigran Shmis. 2020. Managing the Impact of COVID-19 on Education Systems Around the World: How Countries Are Preparing, Coping, and Planning for Recovery, The World Bank, March 18, 2020.

Basilaia, G., Kvavadze, D. (2020). Transition to online education in schools during a SARS-CoV-2 coronavirus (COVID-19) pandemic in Georgia. Pedagogical Research， 5(4), 10. https://doi.org/10.29333/pr/7937 Google Scholar

Brianna, D., Derrian, R., Hunter, H., Kerra, B., \& Nancy, C. (2019). Using EdTech to enhance learning. International Journal of the Whole Child, 4(2), 57-63.

Casey, L., Bruce, B.C. (2010) Sustaining the Inquiry Cycle: Digital literacy reframed, in Gibson, D., Dodge, B. (Eds) Proceedings of Society for Information Technology \& Teacher Education International Conference 2010, pp. 1372-1379. Chesapeake, VA: AACE. http://www.editlib.org/p/33548; http://www.editlib.org/p/33548

Google Scholar

Cluver L. Parenting in a time of COVID-19. Lancet. 2020;395(2020): E64. [PMC free article] [PubMed] [Google Scholar]

Dhawan, S. (2020). Online learning: A panacea in the time of COVID-19 crises. Journal of Educational Technology, 49(1), 5-22. https://doi.org/10.1177/0047239520934018

Google Scholar

Doucet, A., Netolicky, D., Timmers, K., Tuscano, F. J. (2020). Thinking about pedagogy in an unfolding pandemic (An Independent Report on Approaches to Distance Learning during COVID-19 School Closure). Work of Education International and UNESCO. https://issuu.com/educationinternational/docs/2020_research_covid -19_eng. Google Scholar

Favale, T., Soro, F., Trevisan, M., Drago, I., \& Mellia, M. (2020). Campus traffic and eLearning during COVID-19 pandemic. Computer Networks, 176, 107290.

García, Emma, Elaine Weiss, and Lora Engdahl. 2020. "Access to Online Learning Amid Coronavirus Is Far from Universal, and Children Who Are Poor Suffer from a Digital Divide." Working Economics Blog (Economic Policy Institute), April 17, 2020.

Greeley, Christopher S. 2020. “Child Maltreatment Prevention in the Era of Coronavirus Disease 2019.”JAMA

Pediatrics. Published online August 03, 2020. Thtps://doi.org/10.1001/ jamapediatrics.2020.2776.

Hodges, C.B., Moore, S.L., Lockee, B.B., Trust, T., Bond, M.A. (2020, March 27). The difference between emergency remote teaching and online learning. EDUCAUSE Review. https://tinyurl.com/rekxcrq

Lazarus, J. V. et al. COVID-SCORE: a global survey to assess public perceptions of government responses to COVID19 (COVID-SCORE-10). PLOS ONE 15, e0240011 (2020). 
Mantiri, O., Hibbert, G. K., \& Jacobs, J. (2019). Digital literacy in ESL classroom. Universal Journal of Education Research 7(5), 1301-1305. Retrieved from

http://www.hrpub.org DOI: 10.13189/ujer.2019.070515

Murgatrotd, S. (2020, March). COVID-19 and Online learning, Alberta, Canada.

doi:10.13140/RG.2.2.31132.8512. Google Scholar

Petrie (2020), "Covid-19 and the Australian Human Rights Acts. https://orcid.org/0000-0003-1061-2863

Pew Research Center, 2021, "Social Media Use in 2021", Survey of US Adults Conducted January 25 - February 8, 2021

Sintema, E. J. (2020 April 7). Effect of COVID-19 on the performance of grade 12 students: Implications for STEM education. EURASIA Journal of Mathematics, Science and Technology Education, 16(7).

https://doi.org/10.29333/ejmste/7893. Google Scholar

Stratford, Brandon. 2020. As Schools Reopen, Addressing COVID-19-Related Trauma and Mental Health Issues Will Take More Than Mental Health Services. Child Trends, July 2020.

Tinubu Ali, Titilayo, and Mirel Herrera. 2020. Distance Learning During COVID-19: 7 Equity Considerations for Schools and Districts. Southern Education Foundation, April 2020.

UNESCO. Education: From Disruption to Recovery. (2020). Available online at:

https://en.unesco.org/covid19/educationresponse (accessed May 24, 2020).

United States Federal Communications Commission (FCC), 2014

Widana, I. (2020). The effect of digital literacy on the ability of teachers to develop HOTS-based assessment. Journal of Physics: Conference Series. 1503. 012045. 10.1088/1742-6596/1503/1/012045. 